\title{
Photodegradation of 2,4-Dichlorophenol in Aqueous Systems under Simulated and Natural Sunlight
}

\author{
Dorota Gryglik, ${ }^{1}$ Marta Gmurek, ${ }^{2}$ Magdalena Foszpańczyk, ${ }^{2}$ and Stanisław Ledakowicz ${ }^{2}$ \\ ${ }^{1}$ Faculty of Civil Engineering, Architecture and Environmental Engineering, Lodz University of Technology, Aleja Politechniki 6, \\ 90-924 Lodz, Poland \\ ${ }^{2}$ Faculty of Process and Environmental Engineering, Lodz University of Technology, Ulica Wólczańska 213, 90-924 Lodz, Poland \\ Correspondence should be addressed to Dorota Gryglik; dorota.gryglik@p.lodz.pl
}

Received 26 February 2016; Revised 23 April 2016; Accepted 4 May 2016

Academic Editor: Irene Michael

Copyright (c) 2016 Dorota Gryglik et al. This is an open access article distributed under the Creative Commons Attribution License, which permits unrestricted use, distribution, and reproduction in any medium, provided the original work is properly cited.

\begin{abstract}
The work presents results of studies on 2,4-dichlorophenol (2,4-DCP) degradation in aqueous solutions using photochemically initiated processes by simulated and natural sunlight. A number of possible substrate photodegradation routes were investigated, by both direct photolysis and photosensitized oxidation process. The major role of singlet oxygen in 2,4-DCP photodegradation was proved. Rose Bengal and derivatives of porphine and phthalocyanine were used as sensitizers. The influences of various process parameters on the reaction rate were investigated. On the basis of experimental data reaction rate constants of 2,4-DCP photosensitized oxidation were determined. The possibility of using natural sunlight to degrade 2,4-DCP in water in the middle latitudes was stated. The acute toxicity bioassay was conducted with the marine bacterium Vibrio fischeri as a bioluminescent indicator. The obtained results encourage further research on this process.
\end{abstract}

\section{Introduction}

The pollution of aquatic environment by trace amounts of anthropogenic chemical substances has a hazardous impact on the regular development of plants and animals as well as on the human health [1]. Dichlorophenols are widely used in organic synthesis for the production of pharmaceuticals, disinfectants, preservatives, insecticides, fungicides, and herbicides [2]. They are attractive initial substrates which are used in industry, for example, for the production of higher chlorophenols [3]. 2,4-Dichlorophenol (2,4-DCP) is a compound characterized by high toxicity to living organisms so even the small amount released into the environment can pose serious consequences $[4,5]$. It is well known that very low levels of chlorophenols in water cause significant deterioration of its taste and smell. Contamination by 2,4DCP in environment may occur as a result of degradation of herbicides, for example, 2,4-dichlorophenyl-p-nitrophenyl ether, from chlorination of drinking water and industrial and municipal waste water by water disinfection plants or from agricultural runoff or industrial waste discharges $[2,6,7]$.
2,4-DCP has also been reported to be an endocrine disruptor [8]. Thus, it is important to protect the environment from the harmful effects of its presence. Unfortunately, the conventional treatment methods are not able to degrade these xenobiotics efficiently.

Recently the use of advanced oxidation processes using different chemical and photochemical processes for the purification of wastewater or water treatment has become very popular. The main mechanism of compound degradation by these methods is the hydroxyl radical generation and utilization. Thus, they are very effective in removing micropollutants (also microorganisms) present in the wastewater, especially when these are found in low concentrations $[9,10]$. Moreover, among the photochemical routes of many xenobiotics degradation the most popular one is solar photocatalytic irradiation of the substrate in the presence of $\mathrm{TiO}_{2}$ as a catalyst [11]. There are reports in this topic concerning 2,4DCP degradation $[12,13]$. However, in many cases, advanced oxidation processes have limited practical applications due to high cost and energy consumption and so forth. 
An alternative process seems to be the photosensitized oxidation process, particularly using molecular oxygen. It involves the absorption of the visible light energy by the photosensitizer to bring it to a reactive excitation state, transferring its excitation energy to the surrounding molecules. It can occur according to two different photochemical mechanisms: type I (as electron or hydrogen atom transfer), type II photooxidation (as energy transfer to the oxygen molecule and generating reactive singlet oxygen form), or a combination of both. The domination of any of these mechanisms is dependent on many factors including the nature of the substrate and of the sensitizer and the properties of their microenvironment. Thus, the sensitizer acts here, in principle, as a specific kind of catalyst which enables the reaction to occur while remaining unchanged itself.

It is important to note that in this process the photosensitizer may be used in homogeneous solution or may be immobilized on various kinds of carriers $[14,15]$. The use of a soluble form of the sensitizer is faster, simpler, and cheaper. However, it is associated with the introduction of a new component to the solution. It is, in fact, an additional "pollution" introduced into the water which may have itself more toxic properties or the products of its decomposition may be, for example, more toxic and so forth. Thus, by purifying the water environment it can cause unwanted damage the consequences of which can be unpredictable. The use of the sensitizer in the immobilized form can avoid the aforementioned drawbacks because it is easily separated after the reaction. Its additional useful and valuable quality is that it could be reused. Unfortunately, the use of the dye in the immobilized form is usually more difficult to implement, definitely more time-consuming, and generally more expensive.

Herein we present results of photooxidation of 2,4dichlorophenol under simulated and natural sunlight via singlet oxygen generated by various excited photosensitizers in homogeneous solutions. The objective is to define the conditions that maximize the rate of photosensitized degradation of 2,4-DCP in the aquatic solution, to determine the kinetic constants, and to compare the photodegradation rate under simulated and natural sunlight.

\section{Materials and Methods}

All chemicals were commercially available products. The model pollutant 2,4-dichlorophenol ( $\geq 99 \%$ ) was purchased from Aldrich. Sodium azide $\left(\mathrm{NaN}_{3}\right)$ and tert-butanol $(t$ $\mathrm{BuOH})$ were purchased from Fluka and superoxide dismutase (SOD) was purchased from Sigma Aldrich.

The $\mathrm{pH}$ of mixtures during experiments was maintained stable using a buffer solution (according to BrittonRobinson). All buffer reagents $\mathrm{H}_{3} \mathrm{PO}_{4}, \mathrm{H}_{3} \mathrm{BO}_{3}, \mathrm{CH}_{3} \mathrm{COOH}$, and $\mathrm{NaOH}$ were p.a. quality (POCH, Poland). Samples for chromatographic analysis were acidified with $0.5 \mathrm{M}$ phospho$\operatorname{ric}(\mathrm{V})$ acid (p.a. POCH, Gliwice).

All reaction solutions were prepared in distilled water (Millipore Milli-Q Plus System, 18.2 M $\Omega$ ).
2.1. The Sensitizers. The following dyes were used as photosensitizers:

(i) Rose Bengal, RB, was purchased from Fluka;

(ii) aluminum(III) phthalocyanine chloride tetrasulfonic acid, $\mathrm{AlPcS}_{4}$, was purchased from Frontier Scientific Inc. (Logan, USA);

(iii) mesotetrasulphonato phenyl porphyrin, $\mathrm{TPPS}_{4}$, was purchased from Fluka (Steinheim, Germany);

(iv) zinc(II) phthalocyanine tetrasulfonate tetrasodium salt, $\mathrm{ZnPcS}_{4}$, was purchased from Frontier Scientific Inc. (Logan, USA).

The important physicochemical properties of the dyes which allow them to act as efficient photosensitizers (PS) are presented in Table 1.

2.2. Lamp Irradiation Setup. The experiments were conducted in a semicontinuous system in flat reactors $(0.06 \times$ $0.10 \mathrm{~m}$ ) of the volume of $0.01 \mathrm{dm}^{3}$ each one. Five reactors were symmetrically positioned around the xenon lamp (Osram $100 \mathrm{~W}, E_{0}=324 \mu$ Einstein $\mathrm{s}^{-1} \mathrm{dm}^{-3}$ ), simulating solar radiation. The quantity of absorbed photons was calculated using Reinecke's actinometer for wavelengths ranging from $310 \mathrm{~nm}$ to $770 \mathrm{~nm}$. The reaction mixture in each reactor was agitated by gentle air or oxygen stream. The initial concentration of 2,4-DCP was equal to $2 \times 10^{-4} \mathrm{M}$ and the sensitizers (RB, $\mathrm{TPPS}_{4}, \mathrm{AlPcS}_{4}$, and $\mathrm{ZnPcS}_{4}$ ) were used at initial concentration equals $2 \times 10^{-5} \mathrm{M}$.

2.3. Sunlight Irradiation Setup. The photochemical experimental setup with natural sunlight consisted of a glass reactor with a cooling jacket, equipped with a porous plate to deliver air into the reaction solution. Experiments were carried out in a semibatch mode. The volume of mixture was equal to $0.5 \mathrm{dm}^{3}$ and it was buffered to maintain constant $\mathrm{pH}$ during irradiation. Experiments were performed always at the same time of the day (between 10 a.m. and 2 p.m.) at various atmospheric conditions. The spectrum of light was collected with an Oceans Optics USB 4000 fiber optic spectrometer with an approximate resolution of $0.4 \mathrm{~nm}$.

2.4. Analysis. The 2,4-DCP decay was monitored by HPLC (Waters) equipped with a UV diode array detector and a NovaPak 150/C18 column. The wavelength for the UV detection of 2,4-DCP was equal to $284 \mathrm{~nm}$. A mixture of methanol and acidified water $\left(0.01 \% \mathrm{H}_{3} \mathrm{PO}_{4}\right)$ was used as an eluent (70:30 vol./ vol.) at the constant flow rate equal to $0.7 \mathrm{~mL} \mathrm{~min}^{-1}$.

The acute toxicity bioassay was conducted using a Microtox ${ }^{\circledR}$ Model 500 analyzer (Modern Water, New Castle, DE, USA) with the marine bacterium Vibrio fischeri as a bioluminescent indicator. The Microtox $81.9 \%$ screening test and the $81.9 \%$ basic test protocols available with the MicrotoxOmni ${ }^{\mathrm{TM}}$ analyzer software were used for the toxicity assessment of the samples. The decrease in bacteria activity as function of the luminescence was measured after 15 minutes of exposure. The evaluation of the acute toxicity toward $V$. fischeri was presented as inhibition of the luminescence (screening test) as well as the standard index, median of the effective concentration $\left(\mathrm{EC}_{50}\right)$. 
TABLE 1: The physicochemical properties of the dyes used in experiments [16-20].

PS Structure<smiles>[M]OC(=O)c1c(Cl)c(Cl)c(Cl)c(Cl)c1-c1c2cc(I)c(=O)c(I)c-2oc2c(I)c(O[M])c(I)cc12</smiles>

$\mathrm{RB}$
$\varphi_{\Delta}$

0.76

0.98

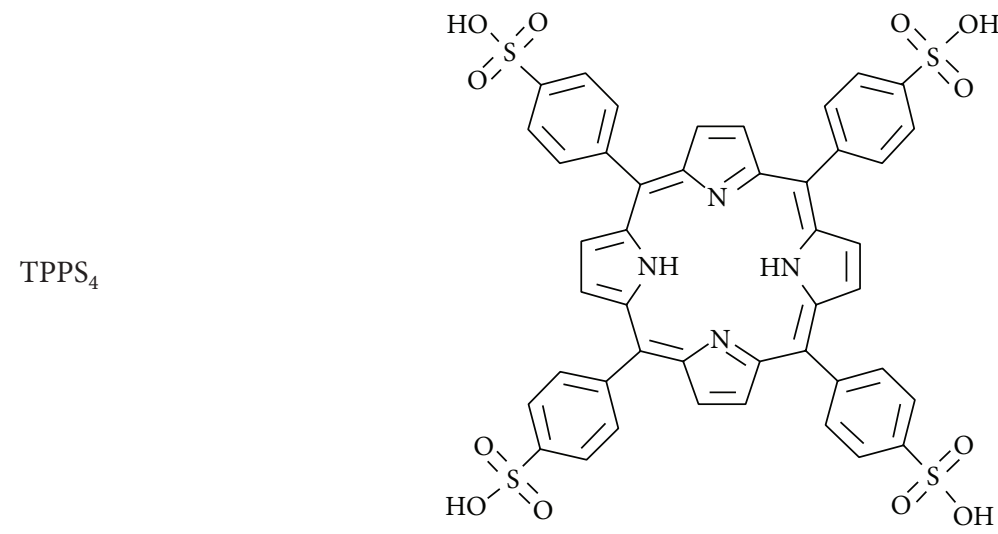

$\mathrm{AlPcS}_{4}$
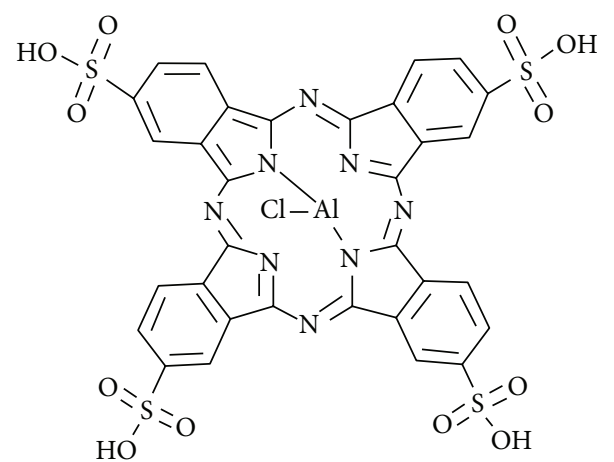

$\mathrm{ZnPcS}_{4}$

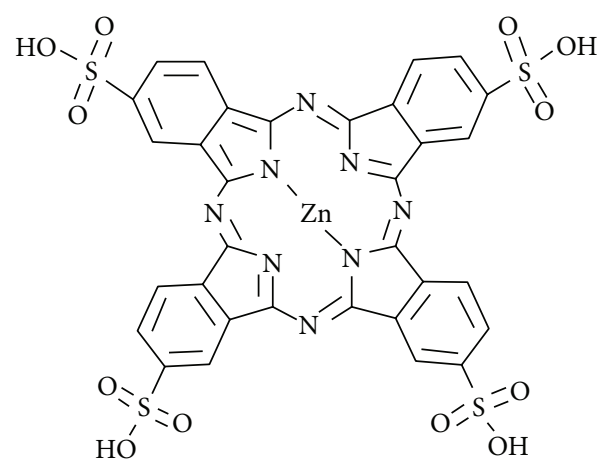



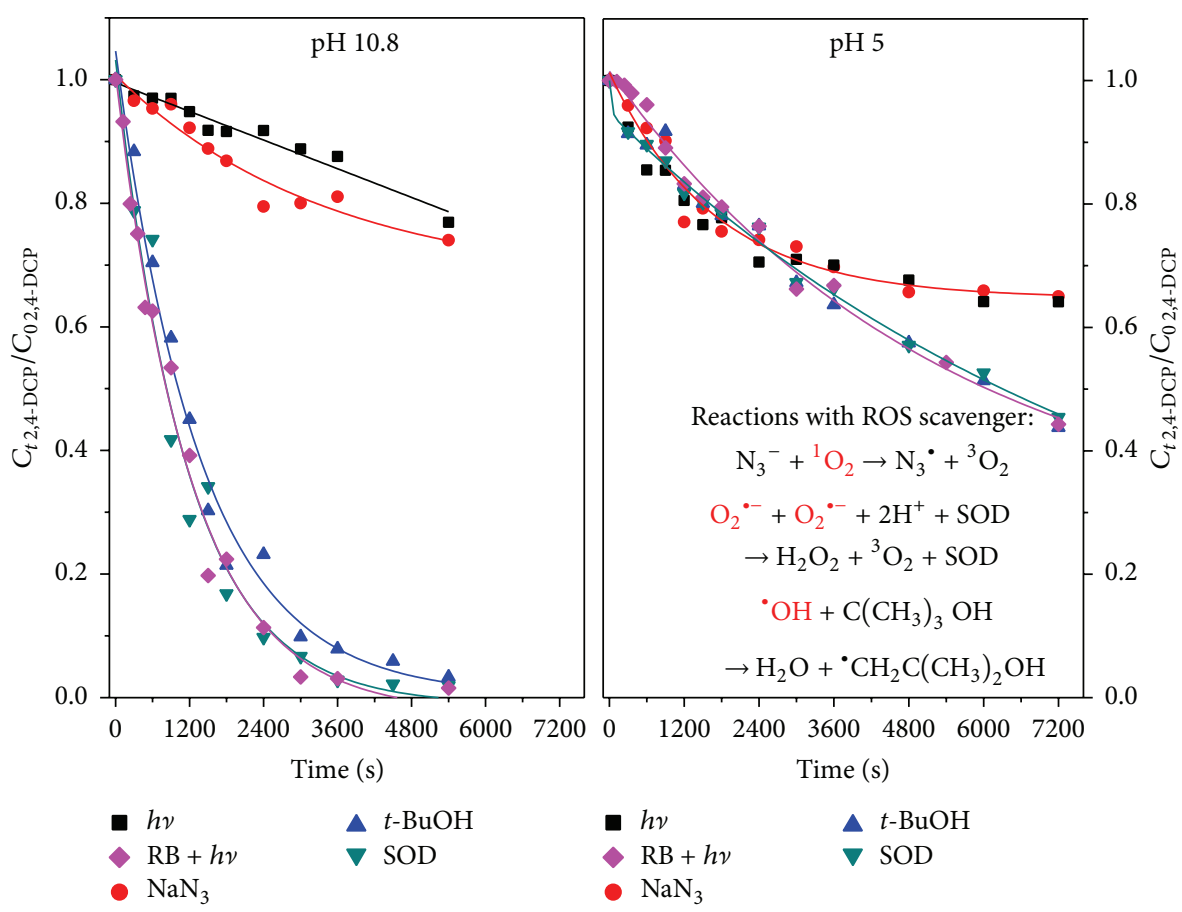

FIgURE 1: The dependence of 2,4-DCP relative concentrations decay on $\mathrm{pH}$ of reaction solution and presence of various ROS scavengers $\left(C_{02,4-\mathrm{DCP}}=2.4 \times 10^{-4} \mathrm{M}, C_{0 \mathrm{RB}}=2 \times 10^{-5} \mathrm{M}, C_{0 \mathrm{NaN}_{3}}=2.4 \times 10^{-4} \mathrm{M}, C_{0 t-\mathrm{BuOH}}=2.4 \times 10^{-4} \mathrm{M}, C_{0 \mathrm{SOD}}=2.4 \times 10^{-4} \mathrm{M}\right.$, air bubbling, and xenon lamp irradiation).

\section{Results and Discussion}

3.1. Lamp Irradiation. In our previous experiments a large dependence of the sensitized oxidation reaction rate on $\mathrm{pH}$ of reaction mixture has been found. It is probably connected with $\mathrm{pH}$-dependent degree of compound dissociation [14, 21]. Irradiation of 2,4-DCP in the presence of oxygen and a sensitizer confirmed these observations. It seems that the substrate degradation is fastest in taking place in alkaline solutions and the acidic medium does not increase the rate of the reaction. As shown in Figure 1 in $\mathrm{pH} 10.8$ the 2,4DCP concentration disappears after approx. 90 minutes of exposure in the presence of $\mathrm{RB}$ and air. At the same time in solution at $\mathrm{pH} 5$ the concentration of 2,4-DCP disappears only approx. $45 \%$ relative to its initial value.

Following irradiation of 2,4-DCP by xenon lamp in the absence of the dye compound we recognized that the direct photolysis process is responsible for the disappearance of the substrate in about 20\% (Figure 1).

To fully characterize the photosensitized oxidation of 2,4DCP we have to take into account as much as possible reactions which can occur during irradiation of the solution in the presence of sensitizer and oxygen. It is well known that during photosensitized oxidation process also other reactive oxygen species (ROS) are produced such as the oxygen anion-radical $\left(\mathrm{O}_{2}{ }^{--}\right)$or the hydroxyl radical $(\mathrm{OH})$. Therefore the special additives were added to the reaction solution to explain which way the reaction is undergoing. First the irradiation was conducted in the presence of ${ }^{1} \mathrm{O}_{2}$ scavenger, sodium azide $\left(\mathrm{NaN}_{3}\right)$. The results of this experiment are presented in Figure 1. Evidently the reaction was stopped at photolysis level when $\mathrm{NaN}_{3}$ was used. It suggests that the only reactive oxygen species present in the system are molecules of singlet oxygen and only they are responsible for degradation of the compound. To prove this hypothesis further experiments were carried out with addition of the ${ }^{\circ} \mathrm{OH}$ scavenger tertbutanol $(t-\mathrm{BuOH})$ and superoxide dismutase (SOD) which removes $\mathrm{O}_{2}{ }^{--}$. In this case, the results are quite different: the presence of $t$ - $\mathrm{BuOH}$ in the solution has little effect on slowing down reaction, while SOD has almost no influence on the course of the reaction, which only confirms our assumption.

Three factors must coexist in solution for the occurrence of photosensitized oxidation of a substrate: light, oxygen, and sensitizer. In the next series of experiments we tested whether the oxygen presence/concentration in the solution and type of photosensitizer really affect the reaction progress. As can be seen in Figure 2 the higher the concentration of oxygen in the solution is, the faster the 2,4-DCP concentration decreases.

As can be seen in Figure 2 the decay of 2,4-DCP is 3 times faster when pure oxygen was used. It should be noted that when the reaction solution was not bubbled (any oxygen was delivered), the reaction was inhibited. When the soluble oxygen was consumed the reaction was stopped.

In Figure 3, the influence of the photosensitizer is presented. In the optimum conditions, in which the decay rate of the substrate was fastest, the irradiations were carried out in the presence of various sensitizers. The best results 


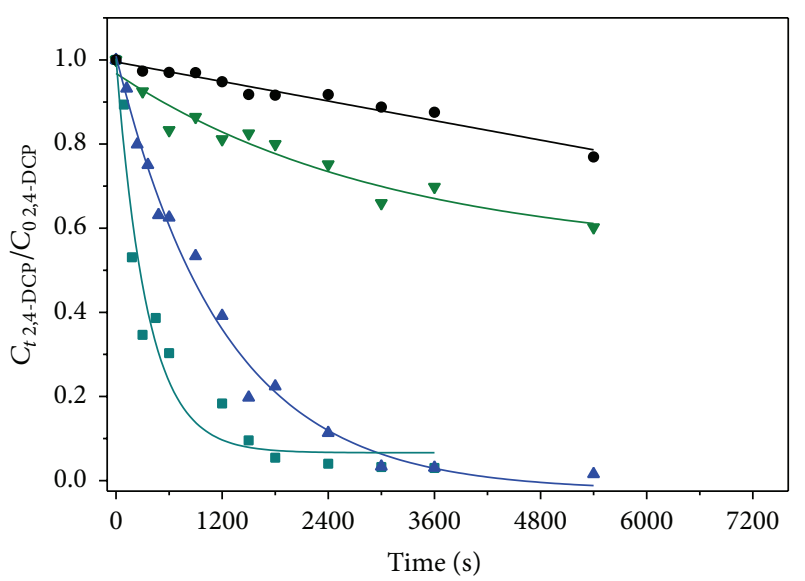

- $h v$

$\Delta h v+\mathrm{RB}+\mathrm{O}_{2}(21 \%)$-bubbling

v $h v+\mathrm{RB}+\mathrm{O}_{2}(\sim 1 \%)$-dissolved $\cdot h v+\mathrm{RB}+\mathrm{O}_{2}(100 \%)$-bubbling

Figure 2: The dependence of 2,4-DCP relative concentrations decay on the concentrations of oxygen in the system $\left(C_{02,4-\mathrm{DCP}}=2.4 \times\right.$ $10^{-4} \mathrm{M}, \mathrm{C}_{0 \mathrm{RB}}=2 \times 10^{-5} \mathrm{M}, \mathrm{pH}=10.8$, and xenon lamp irradiation).

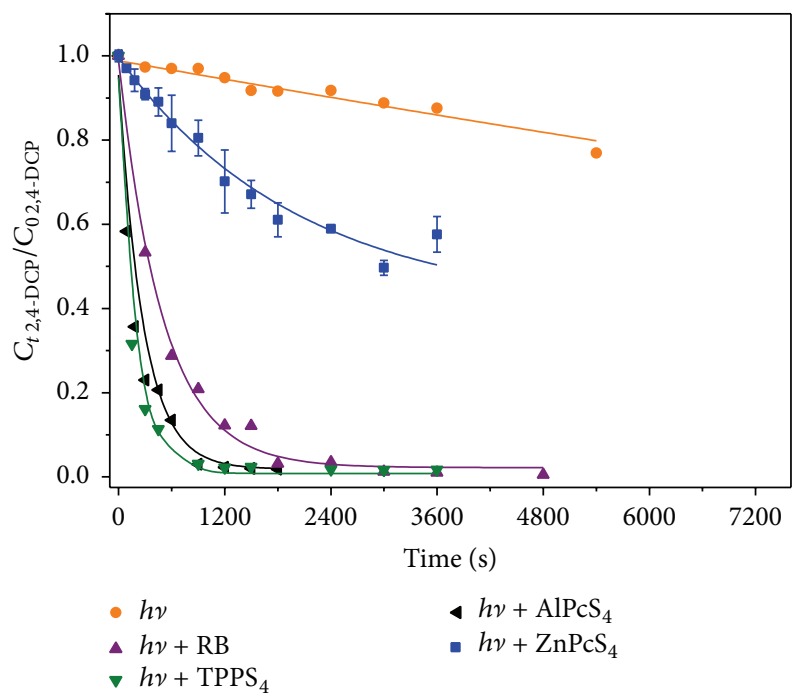

Figure 3: The dependence of 2,4-DCP relative concentrations decay on the type of used photosensitizer $\left(C_{02,4-\mathrm{DCP}}=2.4 \times 10^{-4} \mathrm{M}\right.$, $C_{0 \text { sens. }}=2 \times 10^{-5} \mathrm{M}, \mathrm{pH}=10.8$, oxygen bubbling, and xenon lamp irradiation).

were achieved for $\mathrm{TPPS}_{4}$ while the slowest reaction progress was observed for $\mathrm{ZnPcS}_{4}$. These results have not really confirmed any theoretical suppositions we could pull out on the basis of singlet oxygen quantum yields $\left(\varphi_{\Delta}\right)$ and triplet quantum yields $\left(\varphi_{\mathrm{T}}\right)$ of each sensitizer (Table 1$)$. There are no explicit interactions between these values (which indicate the theoretical ability to generate singlet oxygen) and effectiveness of the dye as specific catalysts in photosensitized oxidation of 2,4-DCP. Interpretation of such results is difficult and additional research is required to fully understand the nature of this phenomenon.
TABLE 2: Determined constant values (mean) of $\mathrm{pH}$ dependence of the reaction.

\begin{tabular}{lcc}
\hline $\begin{array}{l}\text { Constant of reaction } \\
\left(\mathrm{M}^{-1} \mathrm{~s}^{-1}\right)\end{array}$ & $\mathrm{pH} \mathrm{5}$ & $\mathrm{pH} 10.8$ \\
\hline$k_{r}$ & $1.65 \times 10^{6}$ & $3.64 \times 10^{7}$ \\
$k_{\mathrm{t}}$ & $1.05 \times 10^{8}$ & $4.95 \times 10^{8}$ \\
\hline
\end{tabular}

3.2. Kinetic Model. We have tried to establish the kinetics of the 2,4-DCP photodegradation process. We have assumed that the following reactions occur during photosensitized oxidation of 2,4-DCP using RB as photosensitizer:

$$
\mathrm{RB}+h v \longrightarrow{ }^{1} \mathrm{RB}^{*} \stackrel{\varphi_{\mathrm{T}} \Delta E_{\mathrm{a}}}{\longrightarrow}{ }^{3} \mathrm{RB}^{*}
$$

the sensitizer excitation

$$
{ }^{3} \mathrm{RB}^{*}+{ }^{3} \mathrm{O}_{2} \stackrel{k_{\Delta}^{\mathrm{O}_{2}}}{\longrightarrow}{ }^{1} \mathrm{O}_{2}+\mathrm{RB}
$$

the energy transfer to oxygen molecule

$$
\begin{aligned}
{ }^{1} \mathrm{O}_{2}+2,4-\mathrm{DCP} \stackrel{k_{r}}{\longrightarrow}{ }^{3} \mathrm{O}_{2}+\text { product } \\
\text { the photooxidation of 2,4-DCP }
\end{aligned}
$$

where $k_{\Delta}^{\mathrm{O}_{2}}$ is rate constant for triplet $\mathrm{RB}$ reaction with oxygen resulting in ${ }^{1} \mathrm{O}_{2}, \mathrm{M}^{-1} \mathrm{~s}^{-1} ; k_{r}$ is rate constant for chemical reaction of singlet oxygen with 2,4-DCP, $\mathrm{M}^{-1} \mathrm{~s}^{-1} ; E_{\mathrm{a}}$ is flux of absorbed photon per unit of the reaction volume, $\mathrm{Es}^{-1} \mathrm{dm}^{-3}$.

The results shown in Figure 1 allow us to suppose that the main mechanism leading to the photodegradation of 2,4-DCP is a process based on a mechanism consisting in the transfer of energy to oxygen molecule. According to that this process can be described by the following equation [22]:

$$
r=-\frac{d C}{d t}=\frac{k_{r} \cdot C \cdot E_{\mathrm{a}} \cdot \phi_{\Delta}}{k_{d}+k_{\mathrm{t}} \cdot C},
$$

where $k_{d}$ is solvent quenching rate constant, $\mathrm{M}^{-1} \mathrm{~s}^{-1} ; k_{\mathrm{t}}$ is total rate constant for physical and chemical decay of ${ }^{1} \mathrm{O}_{2}$ with 2,4-DCP, $\mathrm{M}^{-1} \mathrm{~s}^{-1}$.

To investigate the effect of the initial concentration of substrate on the rate of photosensitized oxidation process, the test was carried out for six initial concentrations of 2,4$\mathrm{DCP}$ in different $\mathrm{pH}$ of the solution (for undissociated and dissociated form) (Figure 4).

The application of (4) for the initial period of reaction allowed us to estimate the values of the constant rate of chemical reaction of ${ }^{1} \mathrm{O}_{2}$. The values are shown in Table 2.

Determined constants of chemical and physical quenching and chemical reaction rate constants have the same order obtained in our earlier research for butylparaben [14].

3.3. Solar Irradiation. Interesting results were obtained in experiments in which the solution containing 2,4-DCP, a sensitizer, and oxygen was exposed to natural sunlight. 


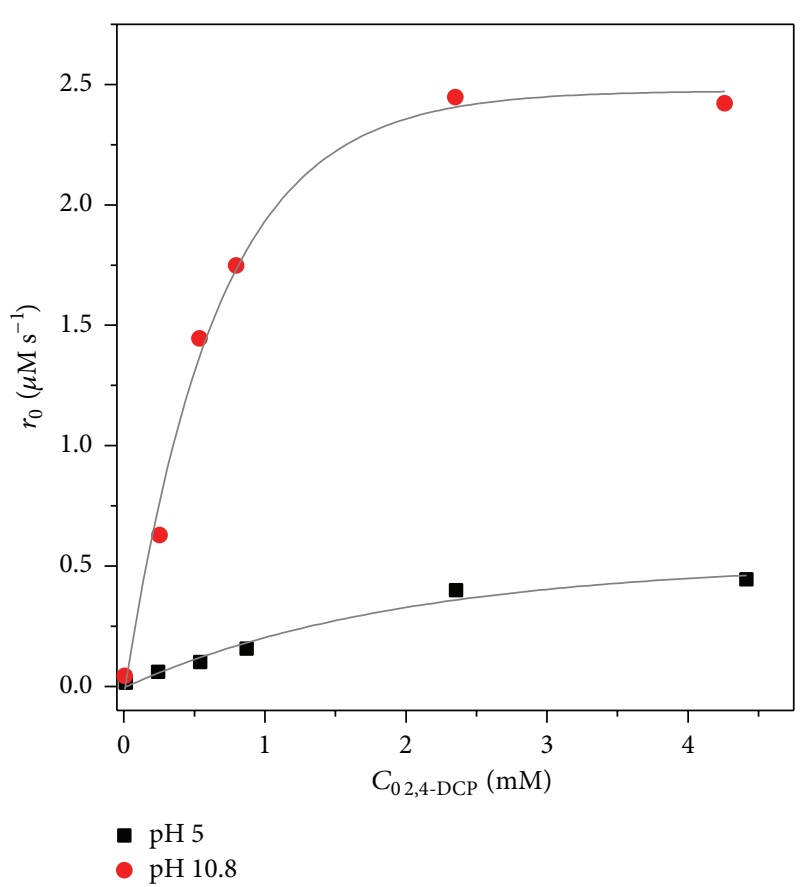

FIgURE 4: The dependence of the reaction rate photosensitized oxidation of the initial substrate concentration of 2,4-DCP using RB as a photosensitizer $\left(C_{0 \text { sens. }}=2 \times 10^{-5} \mathrm{M}\right.$, air bubbling, and xenon lamp irradiation).

The rate of the sensitized oxidation of 2,4-DCP was unexpectedly high. In sunny days complete disappearance of the substrate in alkaline solution in less than 10 minutes was achieved despite the fact that the mixture was bubbled only atmospheric air instead of pure oxygen (Figure 5).

The other observations are in agreement with the previous study with the experiments under the xenon lamp. The major role of singlet oxygen in the degradation of 2,4-DCP was also confirmed (the addition of sodium azide completely stopped the reaction). Similar results were observed in our previous studies with other substrates such as parabens [23], which confirms the applicability of singlet oxygen generated by excited photosensitizers for the photochemical oxidation of xenobiotics in water environments.

There were no marked differences in the substrate decay rate using $\mathrm{TPPS}_{4}, \mathrm{AlPcS}_{4}$, and RB (perhaps in such short reaction time these differences were difficult to notice) while the presence of $\mathrm{ZnPcS}_{4}$ caused a significant inhibition of the degradation rate of 2,4-DCP (Figure 5).

The strong dependence of reaction progress on the $\mathrm{pH}$ of the environment in the range from 5 to 10.8 has also been proven. While in the alkaline solution $(\mathrm{pH}=10.8) 2,4-\mathrm{DCP}$ was almost completely removed after 10 minutes, at $\mathrm{pH}=5$ the photosensitized process resulted only in a $40 \%$ reduction of 2,4-DCP concentration after 2 hours of sunlight irradiation (Figure 6).

The long-term purpose of our work was also to assess the yield of the photosensitized oxidation of 2,4-DCP using natural sunlight in central Poland irradiation conditions.

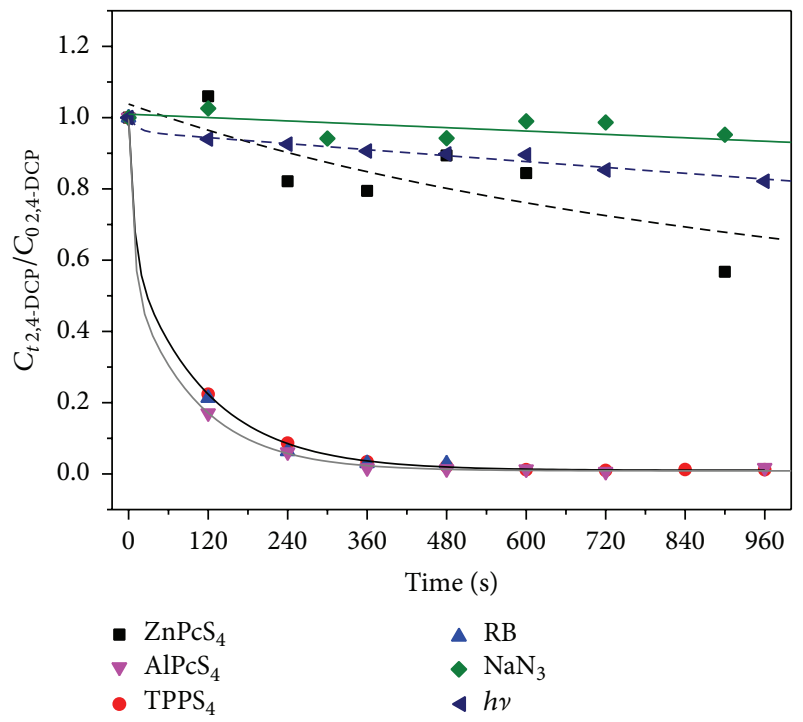

FIGURE 5: The dependence of 2,4-DCP relative concentrations decay on the type of used photosensitizer, in the absence of any sensitizer and in the presence of singlet oxygen scavenger, sodium azide $\left(C_{02,4-\mathrm{DCP}}=2.4 \times 10^{-4} \mathrm{M}, C_{0 \text { sens. }}=2 \times 10^{-5} \mathrm{M}, C_{0 \mathrm{NaN}_{3}}=1 \times 10^{-1} \mathrm{M}\right.$, $\mathrm{pH}=10.8$, air bubbling, and natural sunlight irradiation).

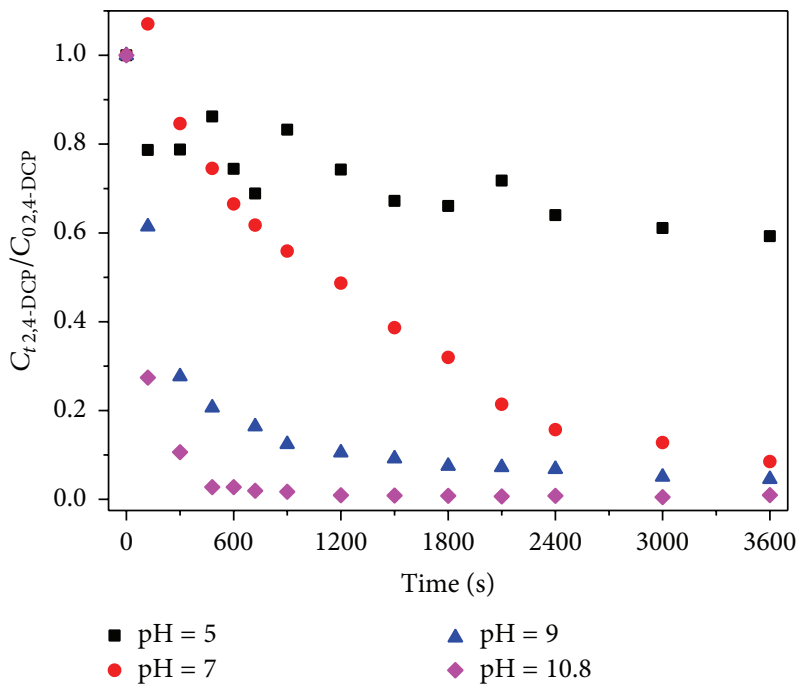

Figure 6: The dependence of 2,4-DCP relative concentrations decay on $\mathrm{pH}$ of solution $\left(C_{02,4-\mathrm{DCP}}=2.4 \times 10^{-4} \mathrm{M}, C_{0} \mathrm{TPPS}_{4}=2 \times 10^{-5} \mathrm{M}\right.$, air bubbling, and natural sunlight irradiation).

Conducting the experiments under various atmospheric conditions both in cloudless days and with semiclouded or completely clouded sky was therefore decided. These investigations were performed in a neutral $\mathrm{pH}$ in order to estimate theoretically the rate of this photoprocess which might occur in natural water due to sunlight in the presence of compounds which may act as sensitizers, for example, humic acids. Several experiments have been made under various weather conditions. The results are shown in Figure 7. 


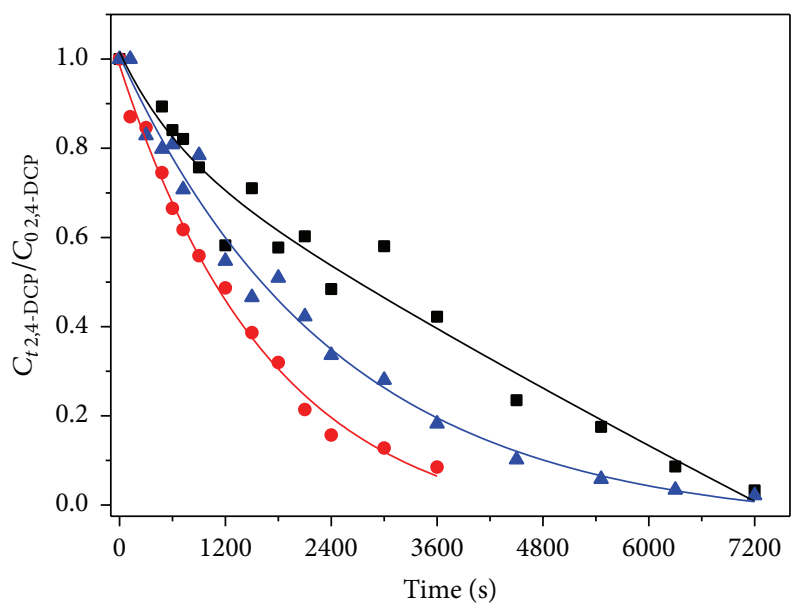

Sun exposure (average intensity of the solar power)

- Sunny day $\left(429 \mathrm{~W} / \mathrm{m}^{2}\right)$

- Sunny/cloudy day $\left(301 \mathrm{~W} / \mathrm{m}^{2}\right)$

- Cloudy day $\left(155 \mathrm{~W} / \mathrm{m}^{2}\right)$

Figure 7: The dependence of 2,4-DCP relative concentrations decay under various sun insolation $\left(C_{02,4-\mathrm{DCP}}=2.4 \times 10^{-4} \mathrm{M}, C_{0 \mathrm{TPPS}_{4}}=2 \times\right.$ $10^{-5} \mathrm{M}, \mathrm{pH}=7$, air bubbling, and natural sunlight irradiation).

It was observed that even in an "unfavorable" (not optimum) $\mathrm{pH}$ of the reaction medium the complete disappearance of 2,4-DCP was achieved after approx. 2 hours of exposure.

In view of obtained results we can state that photosensitized oxidation is effective method of xenobiotic degradation in water environments even in the middle latitude.

As can be seen in Figure 8 the photodegradation under sunlight is much effective than application of lamp as a light source, despite the smaller irradiance intensity. The photosensitized oxidation with $\mathrm{TPPS}_{4}$ required the exposure to $725 \mathrm{~kJ} \mathrm{~m}^{-2}$ radiation to degrade $97 \%$ of initial 2,4-DCP concentration when xenon lamp was applied, whereas during natural sunlight irradiation only $526 \mathrm{~kJ} \mathrm{~m}^{-2}$ radiation was enough to degrade $99 \%$ of the same initial $2,4-\mathrm{DCP}$ concentration. It should be noticed that from an economical point of view the use of natural sunlight can generate smaller technology costs.

3.4. Acute Toxicity Analysis. The toxicity assessment was conducted by a screening test and an $\mathrm{EC}_{50}$ test for the photosensitized oxidation of 2,4-DCP in homogenous aqueous solutions under lamp irradiation. The results of the screening test during treatment time are shown in Figure 9. Based on the toxicity test performed for pure 2,4-DCP the $\mathrm{EC}_{50}$ value was determined to be $2.92 \pm 0.96 \mathrm{mg} \mathrm{L}^{-1}$. The available literature $\mathrm{EC}_{50}$ values toward luminescent bacteria for 2,4-DCP range from 1.24 to $6.06 \mathrm{mg} \mathrm{L}^{-1}[24,25]$. As can be seen in Figure 9, the inhibition of luminescence of $V$. fischeri decreased during the photosensitized oxidation of 2,4-DCP. Although after 10 minutes of the treatment in the reaction mixture 2,4-DCP was very low, the inhibition of the $V$. fischeri luminescence is still high $(\approx 90 \%)$.

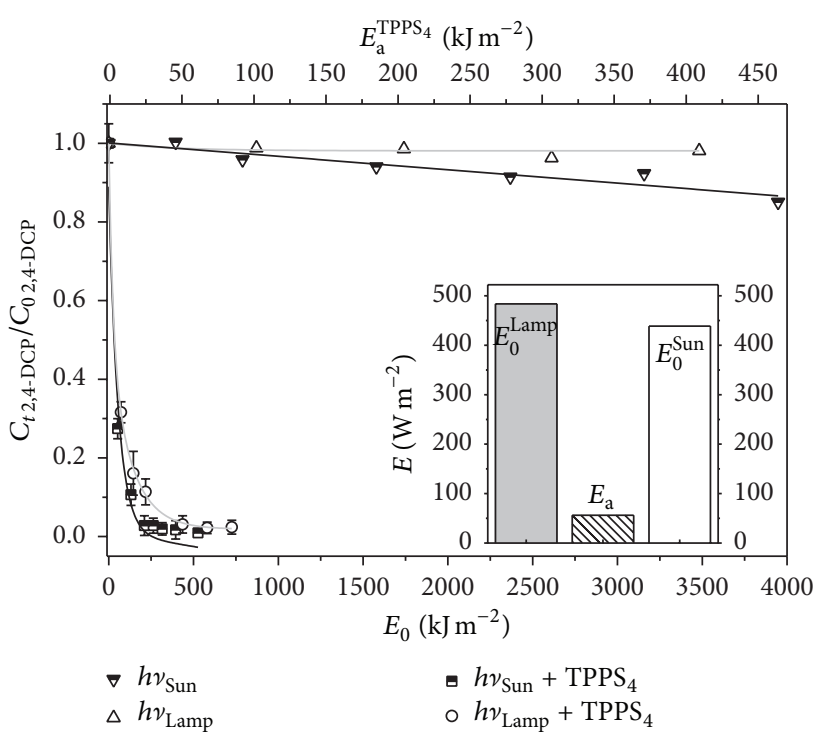

FIGURE 8: Variation in the concentration of 2,4-DCP during photodegradation experiments mediated by $\mathrm{TPPS}_{4}$ and without $\mathrm{TPPS}_{4}$ and induced by solar and lamp radiation. Insert: incident energy $\left(E_{0}\right)$ of radiation for sunlight and lamp and energy absorbed $\left(E_{\mathrm{a}}\right)$ by $\mathrm{TPPS}_{4}$.

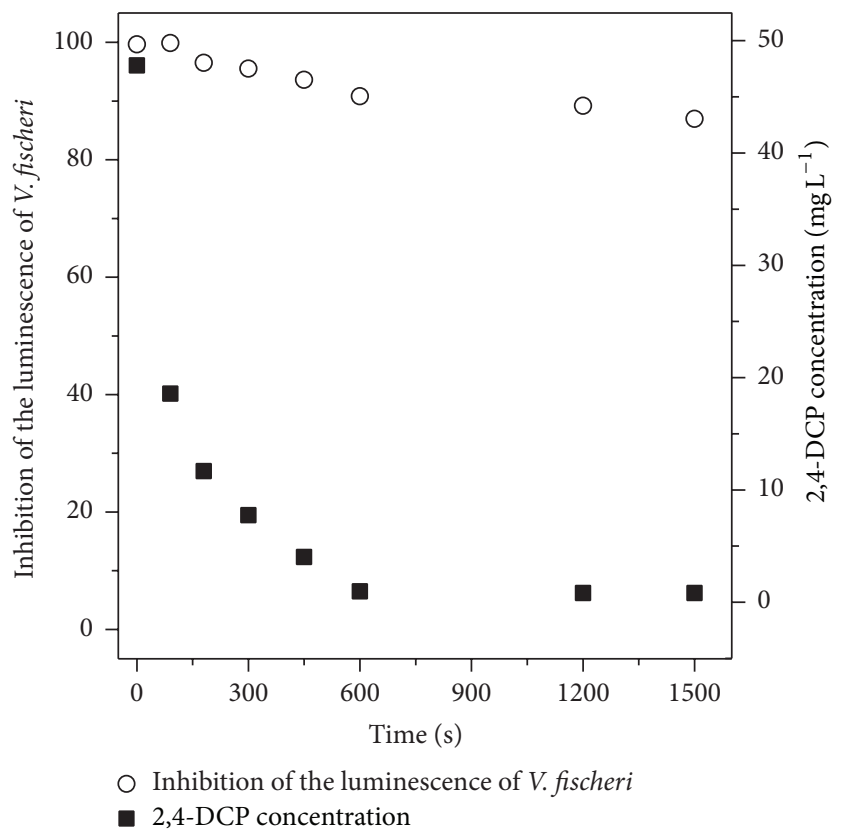

Figure 9: Toxicity analysis of 2,4-DCP photosensitized oxidation.

The determined $\mathrm{EC}_{50}$ values are presented in Table 3. The reaction solution after photosensitized oxidation in homogenous solution indicated lower toxicity. It can be assumed that during photosensitized oxidation less toxic degradation products are formed compared with 2,4-DCP. 
TABLE 3: Determined values of $\mathrm{EC}_{50}$, the effective concentration of the sample that causes $50 \%$ decrease in the light output of the Vibrio fischeri organism under 15 minutes.

\begin{tabular}{lcc}
\hline Time $(\min )$ & $\mathrm{EC}_{50}(\%)$ & $\begin{array}{c}\text { 2,4-DCP conc. in reaction } \\
\text { solution }\left(\mathrm{mg} \mathrm{L}^{-1}\right)\end{array}$ \\
\hline 0 & 2.69 & 47.80 \\
5 & 4.05 & 7.74 \\
10 & 6.06 & 0.96 \\
25 & 9.64 & 0.81 \\
\hline
\end{tabular}

However, it should be noticed that despite a large decrease in the 2,4-DCP concentration (about 60 times) $\mathrm{EC}_{50}$ value has increased slightly (only about 3.5 times). That unfortunately shows that although the transformation products are less toxic than 2,4-DCP, they are still characterized by very high toxicity.

\section{Conclusion}

Degradation of 2,4-DCP in the aqueous solution by photosensitized oxidation in a homogeneous aqueous solution under visible light irradiation is effective. The degradation occurs mainly due to the reaction with a singlet oxygen and to a small extent due to photolysis. The experimental evidence shows that this pathway of 2,4-DCP decomposition can appear to have a higher rate in the alkaline medium. The efficiency of the 2,4-DCP photodegradation strongly depends on the type of photosensitizer, initial concentration of 2,4DCP, and oxygen content in reaction mixture. The toxicity assessment showed that photosensitized oxidation of 2,4DCP resulted in a toxicity decrease.

In our opinion the photooxidation of phenolic compounds by singlet oxygen appears to be an interesting option from both the scientific and technological points of view due to its advantage of using ubiquitous substrates: oxygen from air and solar radiation. The interaction between them frequently occurs in nature, for example, in surface water, where the humic acids could act as the sensitizers.

The possibility of use of air and sunlight creates great opportunities of practical applications. The application of this process for large scale wastewater treatment would require the use of optimum sensitizer concentration, $\mathrm{pH}$ adjustment, and optimization of all other reaction conditions.

\section{Competing Interests}

The authors declare that there are no competing interests regarding the publication of this paper.

\section{Acknowledgments}

This research was supported by the National Science Centre (NCN) in Poland within research project 2012/07/B/ST8/ 03787. Marta Gmurek acknowledges the support from Foundation for Polish Science within the START scholarship.

\section{References}

[1] D. Fatta-Kassinos, I. K. Kalavrouziotis, P. H. Koukoulakis, and M. I. Vasquez, "The risks associated with wastewater reuse and xenobiotics in the agroecological environment," Science of the Total Environment, vol. 409, no. 19, pp. 3555-3563, 2011.

[2] M. Czaplicka, "Sources and transformations of chlorophenols in the natural environment," Science of the Total Environment, vol. 322, no. 1-3, pp. 21-39, 2004.

[3] A. Białek and W. Moszczyński, "Technological aspects of the synthesis of 2,4-dichlorophenol," Polish Journal of Chemical Technology, vol. 11, no. 2, pp. 21-30, 2009.

[4] F. Kargi and S. Eker, "Toxicity and batch biodegradation kinetics of 2,4 dichlorophenol by pure Pseudomonas putida culture," Enzyme and Microbial Technology, vol. 35, no. 5, pp. 424-428, 2004.

[5] X. Jin, J. Zha, Y. Xu, Z. Wang, and S. S. Kumaran, "Derivation of aquatic predicted no-effect concentration (PNEC) for 2,4dichlorophenol: comparing native species data with non-native species data," Chemosphere, vol. 84, no. 10, pp. 1506-1511, 2011.

[6] U. G. Ahlborg, T. M. Thunberg, and H. C. Spencer, "Chlorinated phenols: occurrence, toxicity, metabolism, and environmental impact," Critical Reviews in Toxicology, vol. 7, no. 1, pp. 1-35, 1980.

[7] US Environmental Protection Agency (USEPA), "Ambient water quality criteria for 2,4-dichlorophenol," Tech. Rep. EPA/ 440/5-80-042, USEPA, Washington, Wash, USA, 1980.

[8] X. Y. Zhang, J. M. Zha, W. Li, L. H. Yang, and Z. J. Wang, "Effects of 2,4-dichlorophenol on the expression of vitellogenin and estrogen receptor genes and physiology impairments in Chinese rare minnow (Gobiocypris rarus)," Environmental Toxicology, vol. 23, no. 6, pp. 694-701, 2008.

[9] S. Jiang, J. Zhu, Y. Ding, S. Bai, Y. Guan, and Q. Ye, "Effectiveness and mechanisms of fenton-like $\mathrm{Si}-\mathrm{FeOOH} / \mathrm{H}_{2} \mathrm{O}_{2}$ in 2,4-dichlorophenol wastewater treatment," Ozone: Science \& Engineering, vol. 37, no. 6, pp. 495-502, 2015.

[10] Y. Qiu, C.-H. Kuo, and M. E. Zappi, "Ozonation kinetics of six dichlorophenol isomers," Ozone: Science \& Engineering, vol. 24, no. 2, pp. 123-131, 2002.

[11] I. Dobrosz-Gómez, M. Á. Gómez-García, S. M. López Zamora et al., "Transition metal loaded $\mathrm{TiO}_{2}$ for phenol photo-degradation," Comptes Rendus Chimie, vol. 18, no. 10, pp. 1170-1182, 2015.

[12] A. M. Abeish, H. M. Ang, and H. Znad, "Solar photocatalytic degradation of chlorophenols mixture (4-CP and 2,4-DCP): mechanism and kinetic modelling," Journal of Environmental Science and Health, Part A: Toxic/Hazardous Substances and Environmental Engineering, vol. 50, no. 2, pp. 125-134, 2015.

[13] J.-C. Sin, S.-M. Lam, A. R. Mohamed, and K.-T. Lee, “Degrading endocrine disrupting chemicals from wastewater by $\mathrm{TiO}_{2}$ photocatalysis: a review," International Journal of Photoenergy, vol. 2012, Article ID 185159, 23 pages, 2012.

[14] D. Gryglik, J. S. Miller, and S. Ledakowicz, "Singlet molecular oxygen application for 2-chlorophenol removal," Journal of Hazardous Materials, vol. 146, no. 3, pp. 502-507, 2007.

[15] M. Gmurek, M. Bizukojć, J. Mosinger, and S. Ledakowicz, "Application of photoactive electrospun nanofiber materials with immobilized meso-tetraphenylporphyrin for parabens photodegradation," Catalysis Today, vol. 240, pp. 160-167, 2015. 
[16] F. Wilkinson, W. P. Helman, and A. B. Ross, "Quantum yields for the photosensitized formation of the lowest electronically excited singlet state of molecular oxygen in solution," Journal of Physical and Chemical Reference Data, vol. 22, no. 1, pp. 113-262, 1993.

[17] J. M. Larkin, W. R. Donaldson, T. H. Foster, and R. S. Knox, "Reverse intersystem crossing from a triplet state of rose bengal populated by sequential 532- +1064-nm laser excitation," Chemical Physics, vol. 244, no. 2-3, pp. 319-330, 1999.

[18] T. Nyokong, "Effects of substituents on the photochemical and photophysical properties of main group metal phthalocyanines," Coordination Chemistry Reviews, vol. 251, no. 13-14, pp. 1707-1722, 2007.

[19] L. P. F. Aggarwal, M. S. Baptista, and I. E. Borissevitch, "Effects of $\mathrm{NaCl}$ upon TPPS4 triplet state characteristics and singlet oxygen formation," Journal of Photochemistry and Photobiology A: Chemistry, vol. 186, no. 2-3, pp. 187-193, 2007.

[20] T. Gensch and S. E. Braslavsky, "Volume changes related to triplet formation of water-soluble porphyrins. A laser-induced optoacoustic spectroscopy (LIOAS) study," The Journal of Physical Chemistry B, vol. 101, no. 1, pp. 101-108, 1997.

[21] D. Gryglik, M. Lach, and J. S. Miller, "The aqueous photosensitized degradation of butylparaben," Photochemical \& Photobiological Sciences, vol. 8, no. 4, pp. 549-555, 2009.

[22] J. S. Miller, "Rose bengal-sensitized photooxidation of 2-chlorophenol in water using solar simulated light," Water Research, vol. 39, no. 2-3, pp. 412-422, 2005.

[23] D. Gryglik and M. Gmurek, "The photosensitized oxidation of mixture of parabens in aqueous solution," Environmental Science and Pollution Research, pp. 1-11, 2015.

[24] K. L. E. Kaiser and V. S. Palabrica, "Photobacterium phosphoreum toxicity data index," Water Pollution Research Journal of Canada, vol. 26, no. 3, pp. 361-431, 1991.

[25] R. Zona, S. Schmid, and S. Solar, "Detoxification of aqueous chlorophenol solutions by ionizing radiation," Water Research, vol. 33, no. 5, pp. 1314-1319, 1999. 

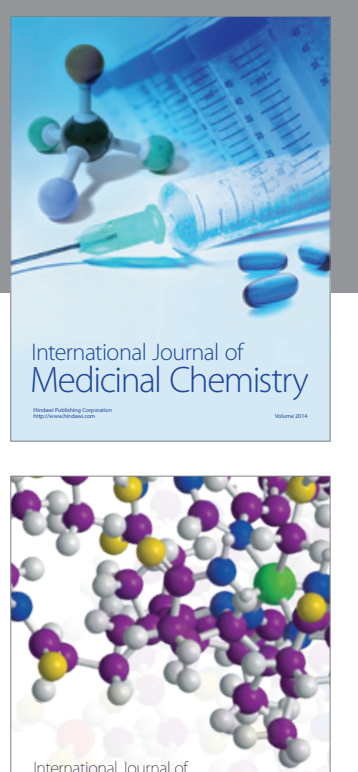

Carbohydrate Chemistry

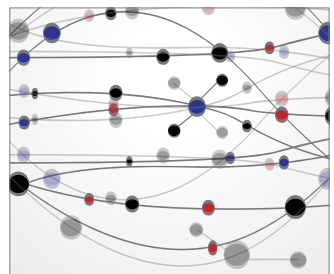

The Scientific World Journal
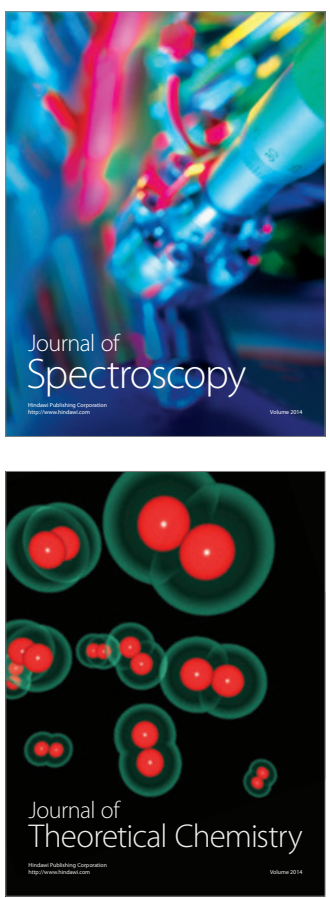
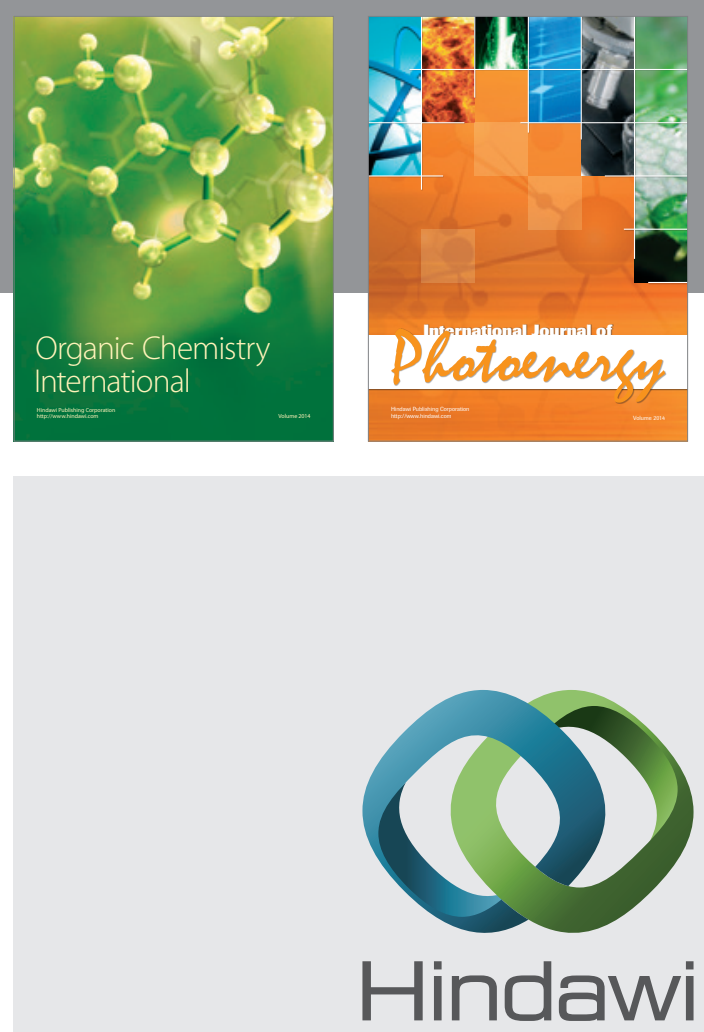

Submit your manuscripts at

http://www.hindawi.com

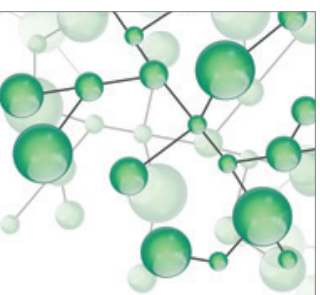

International Journal of

Inorganic Chemistry

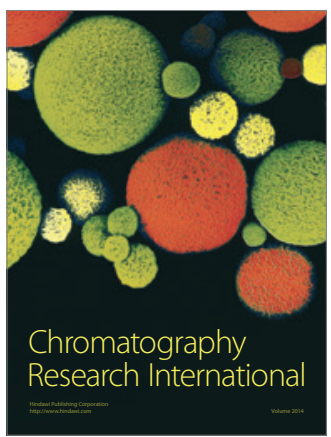

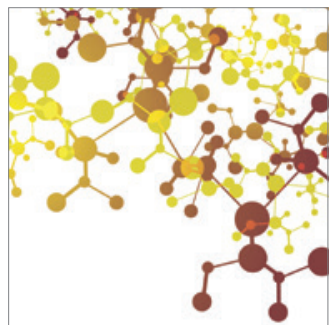

Applied Chemistry
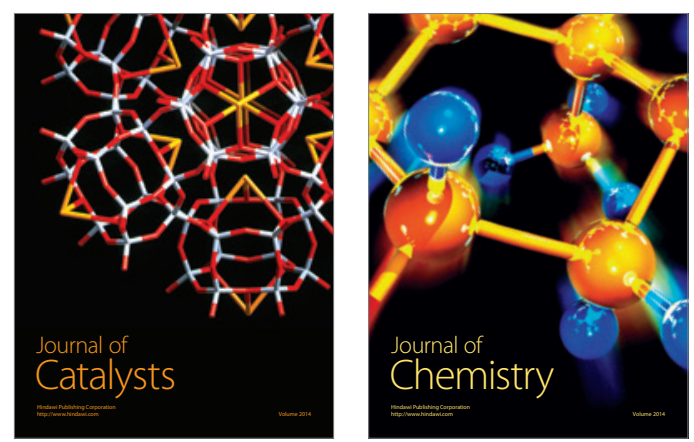
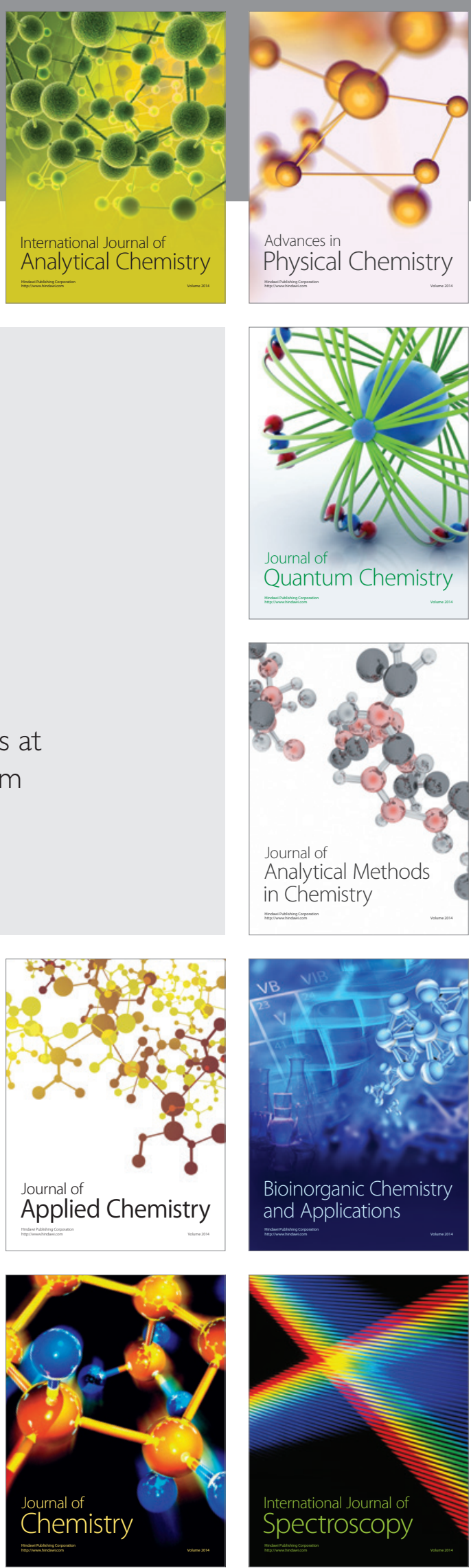